\title{
Coupling heat and chemical tracer experiments for estimating heat transfer parameters in shallow alluvial aquifers
}

\author{
Wildemeersch, S. ${ }^{a}$, Jamin, P. ${ }^{a}, *$, Orban, Ph. ${ }^{a}$, Hermans, T. ${ }^{b, c}$, Klepikova, M. ${ }^{a}$, Nguyen, F. ${ }^{b}$, Brouyère, S. ${ }^{a}$, \\ Dassargues, A. ${ }^{a}$.
}

${ }^{a}$ University of Liege, ArGEnCo, GEO ${ }^{3}$, Hydrogeology and Environmental Geology, Aquapôle, B52/3 SartTilman, 4000 Liege, Belgium

${ }^{b}$ University of Liege, ArGEnCo, GEO3, Applied Geophysics, B52/3 Sart-Tilman, 4000 Liege, Belgium

${ }^{c}$ F.R.S.-FNRS., Research Fellow, Brussels, Belgium

* Corresponding author at: University of Liege, ArGEnCo, GEO³, Hydrogeology and Environmental Geology, Aquapôle, B52/3 Sart-Tilman, 4000 Liege, Belgium. Tel.: +32 (0)43662035. Fax: $+32(0) 43669520$.

E-mail address: pierre.jamin@ulg.ac.be (P. Jamin)

\begin{abstract}
Geothermal energy systems, closed or open, are increasingly considered for heating and/or cooling buildings. The efficiency of such systems depends on the thermal properties of the subsurface.

Therefore, feasibility and impact studies performed prior to their installation should include a field characterization of thermal properties and a heat transfer model using parameter values measured in situ. However, there is a lack of in situ experiments and methodology for performing such a field characterization, especially for open systems. This study presents an in situ experiment designed for estimating heat transfer parameters in shallow alluvial aquifers with focus on the specific heat capacity. This experiment consists in simultaneously injecting hot water and a chemical tracer into the aquifer and
\end{abstract}


monitoring the evolution of groundwater temperature and concentration in the recovery well (and possibly in other piezometers located down gradient). Temperature and concentrations are then used for estimating the specific heat capacity. The first method for estimating this parameter is based on a modeling in series of the chemical tracer and temperature breakthrough curves at the recovery well. The second method is based on an energy balance. The values of specific heat capacity estimated for both methods ( 2.30 and $2.54 \mathrm{MJ} / \mathrm{m}^{3} / \mathrm{K}$ ) for the experimental site in the alluvial aquifer of the Meuse River (Belgium) are almost identical and consistent with values found in the literature. Temperature breakthrough curves in other piezometers are not required for estimating the specific heat capacity. However, they highlight that heat transfer in the alluvial aquifer of the Meuse River is complex and contrasted with different dominant process depending on the depth leading to significant vertical heat exchange between upper and lower part of the aquifer. Furthermore, these temperature breakthrough curves could be included in the calibration of a complex heat transfer model for estimating the entire set of heat transfer parameters and their spatial distribution by inverse modeling.

Keywords: Heat tracer test; Shallow geothermal energy; Very low temperature geothermy, Aquifer thermal energy storage; Heat transfer; Solute transport.

\section{Introduction}

Geothermal energy is a renewable and sustainable energy source particularly attractive in the current context of environmental protection and fighting against climate change. Consequently, shallow geothermal energy systems are increasingly considered for heating and/or cooling buildings (Lund et al., 2011). The main techniques for exploiting shallow geothermal energy are ground source heat pumps (GSHP), which are closed systems with a horizontal or a vertical heat exchanger, and groundwater heat pumps (GWHP), which are open systems requiring a pair of injection and withdrawal wells or a withdrawal well and a discharge through surface water. 
The efficiency of heating systems depends on the hydraulic properties (hydraulic conductivity, porosity, specific yield) and the thermal properties (specific heat capacity, thermal conductivity, and thermal dispersivity) that govern heat transfer in the subsurface. Therefore, prior to their implementation, a feasibility study is recommended. An impact study is also required in some countries to prove compliance of the system with the ongoing regulations (Haehnlein et al., 2010). This impact study is important since such systems induce thermal anomalies in the form of cold or heat plumes in groundwater (Warner and Algan, 1984; Molson et al., 1992; Palmer et al., 1992) which may influence groundwater chemistry (e.g. Jesußek et al., 2013) and microbiology (e.g. Brielmann et al., 2009). This impact study is also important for evaluating the long-term efficiency of the system. These feasibility and impact studies should ideally include a field characterization of the thermal properties of the subsurface and a heat transfer model of the heating system using heat transfer parameter values measured in situ. However, field characterization is often limited and the dimensioning of heating systems is generally based on parameter values found in the literature or on default values of software (e.g. Lo Russo and Civita, 2009; Freedman et al., 2012, Lo Russo et al., 2012, de Paly et al., 2012). This is related to the lack of in situ experiments and methodology available for estimating heat transfer parameters in the subsurface. The thermal response test (TRT) has become very popular for designing closed systems. This test provides an estimation of the effective ground thermal conductivity, including the effects of groundwater flow and natural convection (Gehlin, 2002, Sanner et al., 2005, 2013). The effective ground thermal conductivity is representative for closed systems but not for open systems because the TRT does not take into account the significant influence of withdrawal wells on groundwater flow. Furthermore, the TRT does not provide any estimation of specific heat capacity and thermal dispersivity. Therefore, there is a need for other in situ experiments capable of estimating these parameters. This is particularly important for open systems since heat exchange between the 
groundwater and the aquifer solids is proportional to the specific heat capacity of the saturated porous medium and it modifies the temperature of the pumped groundwater.

The methodology we propose couples heat and chemical tracer experiments. The originality is to simultaneously inject hot water and a chemical tracer into the aquifer and to monitor the evolution of groundwater temperature and tracer concentration in different piezometers located down gradient (including the recovery well). The coupling with a chemical tracer experiment is performed for taking advantage of the similarities between heat transfer and solute transport in porous media in order to facilitate the separation of heat transfer processes and identify related parameters with focus on specific heat capacity. The effective porosity, in particular, simultaneously governs heat transfer by convection and solute transport by advection. Therefore, this parameter is estimated by fitting the chemical tracer breakthrough curve. Given that the effective porosity is known, the temperature breakthrough curve is used for estimating the thermal retardation factor which is proportional to the specific heat capacity of the saturated porous medium, key parameter governing heat exchange between groundwater and aquifer solids.

The use of heat as a groundwater tracer for estimating hydraulic parameters such as hydraulic conductivity is quite usual (Anderson, 2005). However, only a few studies focus on the use of groundwater temperature for estimating heat transfer parameters (Vandenbohede et al., 2009, 2011; Giambastini et al., 2013). These studies are interesting since they show the capabilities and the limitations of such experiments. However, they mainly consist in laboratory experiments in a tank (Giambastini et al., 2013) or in situ experiments with injection of only a small volume of hot water $\left(5.8 \mathrm{~m}^{3}\right)$ (Vandenbohede et al., 2011). Here, we focus on in situ heat tracer experiments with injection of a significant volume of hot water $\left(72 \mathrm{~m}^{3}\right)$ and with a monitoring of the temperature both in the upper and lower parts of the aquifer thanks to a network of double screened piezometers. 
A short presentation of the experimental site is followed by a description of the experimental setup and the methodology. The measured breakthrough curves for the temperature and the chemical tracer are then presented, interpreted, and discussed. The paper ends with the conclusions and the perspectives.

\section{Field site}

The experimental site is located in the small village of Hermalle-sous-Argenteau, $13 \mathrm{~km}$ north-east of the city of Liège in Belgium. The site consists in a vast meadow lying on the alluvial plain of the Meuse River (Figure 1).The alluvial deposits can be divided into four different units. The upper layer is 1 to $1.5 \mathrm{~m}$ thick and is composed of loam with clay lenses. The second unit consists of sandy loam with millimetric gravels which proportion increases with depth down to $3 \mathrm{~m}$ depth. From 3 to $10 \mathrm{~m}$ below ground surface, the third layer is mainly made of alluvial sand and gravels. The gravels to sand ratio increases progressively with depth to reach at the bottom a zone of clean pebbles frequently more than $0.2 \mathrm{~m}$ in diameter. This third layer contains the main mostly unconfined alluvial aquifer. The groundwater table is located approximately $3.2 \mathrm{~m}$ below land surface when not artificially disturbed. The annual fluctuation of the water level in the aquifer is approximately $0.5 \mathrm{~m}$ with the highest levels observed during the month of January. Below the alluvial deposits, low permeability carboniferous shale and sandstone formations are considered as the basement of the alluvial aquifer (Figure 1).

The test site is located between the Albert Canal and the Meuse River. The alluvial aquifer is recharged with water by direct infiltration of rainfall but also from the Albert Canal which basement is not perfectly impervious. The Meuse River imposes the base hydraulic head and constitutes the outflow for the alluvial aquifer. The topography of the site is almost flat and the natural hydraulic gradient in the alluvial aquifer is on the order of $0.06 \%$ directed toward the north-east. Pumping and tracer tests performed in 1999 (Brouyère, 2001; Brouyère, 2003) showed a mean hydraulic conductivity for the alluvial aquifer 
ranging from $2 \times 10^{-2} \mathrm{~m} / \mathrm{s} \mathrm{t} 7 \times 10^{-2} \mathrm{~m} / \mathrm{s}$, a longitudinal dispersivity ranging between 0.5 to $5 \mathrm{~m}$ and an effective porosity from 4 to $8 \%$.

The experimental site includes 1 pumping well and 18 piezometers in total. The pumping well is $0.152 \mathrm{~m}$ of internal diameter and is screened from 3 to $9.5 \mathrm{~m}$ depth. Six piezometers were installed during the years 1980's. They are equipped with PVC tubes of $0.05 \mathrm{~m}$ in diameter and screened within the alluvial gravels. More recently (June 2012), twelve new piezometers were specifically drilled for the purpose of this research. They are located upgradient from the pumping well and organized as three transverse control planes across the main groundwater flow direction, at respective distances of 17,12 and $5 \mathrm{~m}$ from the pumping well. Laterally, the piezometers are separated of approximately $1 \mathrm{~m}$. An injection piezometer is also implanted $20 \mathrm{~m}$ upgradient the pumping well. Nine of the new piezometers are double-screened with a $2 \mathrm{~m}$ lower screen level set at the bottom of the aquifer between 8 and $10 \mathrm{~m}$ depth and an upper screen level placed between 5 and $6 \mathrm{~m}$ depth. The most upgradient injection piezometer and two lateral piezometers from the second (central) transverse control plane are fully screened from 3 to $10 \mathrm{~m}$ depth. Fully screened piezometers were used to monitor the experiment with cross borehole electrical resistivity tomography (Hermans et al., 2015). This technique has recently proved its efficiency to monitor heat injection and storage experiments (Hermans et al., 2012). The detailed setup is presented in Figure 2.

Temperature and hydraulic head surveys were performed during 2011 and 2012 in several piezometers of the site. A continuous monitoring showed a maximum temperature of the groundwater of $13.34^{\circ} \mathrm{C}$ in December and a minimum temperature of $11.91^{\circ} \mathrm{C}$ in June. This variation is indeed in opposition with the annual variation of mean atmospheric temperatures which shows monthly average temperature with a maximum of $18.4^{\circ} \mathrm{C}$ in July and a minimum of $3.3^{\circ} \mathrm{C}$ in January (IRM 2013). 
The only data available on the geothermal properties of the alluvial aquifer in the vicinity of the experimental site come from the ThermoMap project (Bertermann et al., 2013 -

http://www.thermomap-project.eu/). The objective of this project is to map the superficial geothermic resources of Europe by soil and groundwater data. The mapping is performed using empirical laws (Kersten, 1949; Dehner, 2007) for calculating the thermal conductivity and the volumetric heat capacity of the subsurface using soil and groundwater fundamental properties such as bulk density, texture, water content ... These empirical estimations of heat transfer parameters are performed for three horizons: 0 to $3 \mathrm{~m}, 3$ to $6 \mathrm{~m}$, and 6 to $10 \mathrm{~m}$. Results are shown in Table 1.

\section{Experimental setup and methodology}

The tracer experiment was performed under radially converging flow conditions, by pumping at a constant rate of $30 \mathrm{~m}^{3} / \mathrm{h}$ at the recovery well with a Grundfos SP30-3 submersible pump. Drawdown induced by pumping in this very conductive unconfined aquifer was $0.05 \mathrm{~m}$ in the recovery well and $0.04 \mathrm{~m}$ at Pz19 located $5 \mathrm{~m}$ upgradient. $90 \%$ of abstracted groundwater was discharged in a nearby sewage system, outside the study area. The remaining $10 \%$, corresponding to $3 \mathrm{~m}^{3} / \mathrm{h}$, was heated in a fuel boiler (Swingtec Aquamobile DH6) and reinjected as heat tracer together with the chemical tracer at piezometer Pz09. The boiler was theoretically capable of producing a maximum differential of temperature of $30^{\circ} \mathrm{C}$ at a maximum flow rate of $3 \mathrm{~m}^{3} / \mathrm{h}$. During the field experiment, the boiler actually allowed injecting water at a constant temperature of $40^{\circ} \mathrm{C}$ into a groundwater at a natural temperature of $13.33^{\circ} \mathrm{C}$.

Sodium naphtionate (4-Amino-1-naphthalenesulfonic acid sodium salt, CAS $n^{\circ} 130-13-2$ ) was used as a chemical tracer because its specific behavior in the alluvial aquifer of this particular site was well established from previous experiments (Brouyère 2001), with no sorption but significant first-order degradation of $5.5 \cdot 10^{-6} \mathrm{~s}^{-1}$. Sodium naphtionate is a fluorescent dye tracer with absorption and emission 
wavelengths of $325 \mathrm{~nm}$ and $420 \mathrm{~nm}$ respectively. A quantity of $0.4 \mathrm{~kg}$ of naphtionate was used, diluted into $0.1 \mathrm{~m}^{3}$ of water coming from the aquifer, resulting in a concentration of $4000 \mathrm{ppm}$ of naphtionate injected in Pz09 at a rate of 3.9 L/h using a Jesco Magdos LT17 electromagnetic dosing pump in addition to the $3 \mathrm{~m}^{3} / \mathrm{h}$ of heated water.

For heat tracer monitoring, the 18 screens of the 9 piezometers located in the control planes (Pz10 to Pz12, Pz14 to Pz16 and Pz18 to Pz20) were equipped either with SWS MiniDiver or In-Situ Level Troll automated temperature and pressure probes which allowed monitoring hydraulic head and temperatures during all the experiment duration, with a measurement time step of $10 \mathrm{~min}$. The injection piezometer Pz09, Pz13 and Pz17, both located at the extremity of the central control plane were all three equipped with DTS optical fiber (AP-Sensing Linear Pro Series) for temperature logging measurements along the vertical axis of the piezometer. The recovery well was also equipped with an In-Situ Levell Troll probe to monitor the heat tracer breakthrough. Naphtionate was monitored at the recovery well using a GGUN-FL30 field fluorimeter connected in parallel on groundwater discharge with a measurement every $2 \mathrm{~min}$. Available equipment did not allow for monitoring of naphtionate concentrations at the piezometers during the tracer test.

The combined heat - naphtionate tracer injection was performed in Pz09 on October $30^{\text {th }} 2012$ and lasted for $24 \mathrm{~h} 20 \mathrm{~min}$. Monitoring of temperature in the piezometers and at the well was maintained for 14 days.

Pumping at the recovery well was maintained for several weeks after the tracer test. During this time groundwater fluxes were measured using the Finite Volume Point Dilution Method (FVPDM) (Brouyère et al., 2008). This single well dilution method allows a direct measurement of the Darcy's fluxes at each screen of every piezometers at the site.

\section{Results and discussion}




\subsection{Analysis of the breakthrough curves}

The evolution of the temperature measured in each piezometer is presented in Figure 3. The breakthrough curves in blue and in red correspond to the temperatures measured in the lower and in the upper parts of the aquifer, respectively. The green breakthrough curve represent the mean temperature recorded along the thickness of the aquifer by DTS.

The comparison between temperature breakthrough curves in the lower and the upper parts of the aquifer clearly shows that heat pulse travels faster in the lower part of the aquifer. The breakthrough curves in the upper part of the aquifer are also characterized by longer tailings. A maximum temperature change of $14.98^{\circ} \mathrm{C}$ was observed at control plane 1 in the upper part of the aquifer $26 \mathrm{~h}$ after the beginning of the injection. This observation was made in the central piezometer Pz11 located $3 \mathrm{~m}$ down gradient of the injection well. The maximum temperature change in the lower part of the aquifer was only $4.17^{\circ} \mathrm{C}$. This observation was made $27 \mathrm{~h}$ after the beginning of the injection and in the piezometer Pz14 located $8 \mathrm{~m}$ down gradient of the injection well and to the left part of this control plane. At the end of the second control plane, a mean (across the entire screen length) maximum temperature of $5.41^{\circ} \mathrm{C}$ was recorder 1.02 days after the beginning of the injection at the fully screened piezometer Pz13.Except at the first control plane, the highest changes in temperatures are always observed in the lower part of the aquifer. In the upper part, a quick decrease of the temperature change is observed from one plane to the next. On the contrary, in the lower part of the aquifer, the temperature change tends to be slightly higher with the distance from the injection piezometer.

The figure 4 shows the temperatures monitoring and logging at the injection well Pz09 using the DTS. The temperature stratification is obvious with a maximum injection temperature of $40^{\circ} \mathrm{C}$ at the lower part of the piezometer and $34^{\circ} \mathrm{C}$ at the upper part. At the end of the heat tracer injection, the temperature decreases rapidly in the lower part of the piezometer while a significant amount of heat 
remains in the upper part. This is due to a vertical heterogeneity of the groundwater flux in the aquifer that is faster in the lower part of the aquifer leading to a fast flushing of the heat out of the injection piezometer. This is consistent with the lithological observation during the drilling of the piezometer with coarser gravels found at the bottom of the aquifer.

In order to quantify the vertical heterogeneity of the groundwater velocities, Darcy's fluxes have been measured at each screen of every piezometer on the site using the FVPDM technique. Results of the Darcy's fluxes measurements indicates a much faster groundwater flow in the lower part of the aquifer of an order of magnitude (Table 2). The mean Darcy's flux for the upper screens was $2.8 \cdot 10^{-4} \mathrm{~m} / \mathrm{s}$ and $3.3 \cdot 10^{-3} \mathrm{~m} / \mathrm{s}$ for the lower screens, corresponding to the lower part of the aquifer.

The complex evolution of temperature, suggesting that heat transfer is highly sensitive to local heterogeneities of the alluvial aquifer, can be described and interpreted as follows. The temperature breakthrough curves indicate that heat transfer is mainly convective in the lower part of the aquifer and mainly conductive/dispersive in the upper part. As the proportion of gravels in the aquifer progressively increases with depth, the hydraulic conductivity is most probably higher in the lower part of the aquifer. Therefore, the transition from a conductive/dispersive-dominated heat transfer in the upper part to a convection-dominated heat transfer in the lower part is consistent with the geology of the alluvial aquifer. At the same time, the fast convective heat transfer in the lower part and the slow conductive/dispersive heat transfer in the upper part quickly produce a vertical temperature gradient. This vertical temperature gradient leads to heat exchange by conduction from the upper part to the lower part of the aquifer. This represents the first explanation for the progressive temperature increase downgradient in the lower part of the alluvial aquifer. As the vertical temperature gradient progressively decreases with the distance from the injection piezometer, the heat exchange also decreases. Furthermore, due to the pumping, convection is also higher close to the recovery well. The second 
explanation is that the heterogeneity of the alluvial deposit induce preferential flow path that can be deviated from a straight line between injection and recovery well. If the main flow path is considered following as the maximum temperatures reached in the lower part of the aquifer, the flow line should describe a curve through the north-west passing by Pz10, Pz13 or Pz14, and Pz19. This paths correspond, by control planes, to the piezometers showing the highest Darcy's flux measured by the FVPDM technique in their lower screens. This path may correspond to a former curved alluvial channel.

The comparison between the temperature and the naphtionate breakthrough curves in the recovery well clearly shows that heat transfer is delayed and retarded as compared to solute transport (Figure 5). First arrival times are separated by $14 \mathrm{~h}$ and modal times are separated by $25 \mathrm{~h}$. This suggests that heat transfer is slower than solute transport. This can be explained by heat exchange between groundwater and aquifer solids leading to thermal retardation. The comparison also shows that the temperature breakthrough curve seems more dispersed than the naphtionate breakthrough curve. The dispersion of the temperature and naphtionate breakthrough curves is related, respectively, to heat transfer by conduction and by thermal dispersion and to solute transport by molecular diffusion and mechanical dispersion. These heat transfer and solute transport processes can be compared in pairs. This is possible because of the analogy between heat transfer and solute transport equations in porous media. The three-dimensional heat transfer equation in homogeneous porous media that is expressed as (Domenico and Schwartz, 1998):

$\frac{\kappa_{e}}{\rho_{m} c_{m}} \nabla^{2} T-\frac{\rho_{w} c_{w}}{\rho_{m} c_{m}} \nabla(T q)=\frac{\partial T}{\partial t}$

where $T$ is the temperature $[\mathrm{K}], t$ is time $[\mathrm{s}], \rho_{w}$ is the density of the water $\left[\mathrm{kg} / \mathrm{m}^{3}\right], c_{w}$ is the specific heat capacity of the water $[\mathrm{J} / \mathrm{kg} / \mathrm{K}], \rho_{m}$ is the density of the saturated porous medium $\left[\mathrm{kg} / \mathrm{m}^{3}\right], c_{m}$ is the specific heat capacity of the saturated porous medium $[\mathrm{J} / \mathrm{kg} / \mathrm{K}], \kappa_{e}$ is the effective thermal conductivity of the saturated porous medium $[\mathrm{W} / \mathrm{m} / \mathrm{K}]$ and $q$ is the effective velocity $[\mathrm{m} / \mathrm{s}]$. As explained by 
Anderson (2005), among others, the first term in Equation (1) represents heat transfer by conduction, analogous to solute transport by molecular diffusion, as well as heat transfer by thermal dispersion, analogous to hydrodynamic dispersion in solute transport. The term $\frac{\kappa_{e}}{\rho_{m} \times c_{m}}$, including the effects of conduction through the porous medium as well as the effects of thermal dispersion, can be written in an extended form:

$\frac{\kappa_{e}}{\rho_{m} c_{m}}=\frac{n \kappa_{w}+(1-n) \kappa_{s}}{n \rho_{w} c_{w}+(1-n) \rho_{s} c_{s}}+\alpha^{*}|q|=\frac{\kappa_{0}}{\rho_{m} c_{m}}+\alpha^{*}|q|$

where $\rho_{m} \times c_{m}$ is the volumetric heat capacity of the saturated porous medium $\left[\mathrm{J} / \mathrm{m}^{3} / \mathrm{K}\right], n$ is the total porosity $[-], \kappa_{w}$ is the thermal conductivity of the water $[\mathrm{W} / \mathrm{m} / \mathrm{K}], \kappa_{s}$ is the thermal conductivity of the aquifer solids [W/m/K], $\rho_{w} \times c_{w}$ is the volumetric heat capacity of the water $\left[\mathrm{J} / \mathrm{m}^{3} / \mathrm{K}\right], \rho_{s} \times c_{s}$ is the volumetric heat capacity of the aquifer solids $\left[\mathrm{J} / \mathrm{m}^{3} / \mathrm{K}\right], \alpha^{*}$ is the thermal dispersivity $[\mathrm{m}],|q|$ is the effective velocity norm $[\mathrm{m} / \mathrm{s}]$, and $\kappa_{0}$ is the effective thermal conductivity of the saturated porous medium $[\mathrm{W} / \mathrm{m} / \mathrm{K}]$. The term $\frac{\kappa_{0}}{\rho_{m} c_{m}}$, referred as the thermal diffusivity and representing the thermal conduction in the porous medium, is analogous to the molecular diffusion coefficient $D_{m}$ in the solute advection-diffusion equation (Anderson, 2005). When comparing, in porous medium, the orders of magnitude of this thermal diffusivity $\left(10^{-6}\right.$ to $10^{-7} \mathrm{~m}^{2} / \mathrm{s}$ (Domenico and Schwarz, 1998, p. 196) and the order of magnitude of molecular diffusion $\left(10^{-10} \mathrm{~m}^{2} / \mathrm{s}\right)$, it is clear that thermal conduction in heat transfer is far more important than molecular diffusion in solute transport. The term $\alpha^{*}$ is analogous to the dispersivity coefficient $\alpha$ in the solute advection -diffusion equation. However, there is conflicting points of view in the literature on their respective values. For de Marsily (1986), thermal and solute dispersivity are on the same order of magnitude. For Bear (1972), Ingebritsen and Sanford (1998), Hopmans et al. (2002), among others, the effects of thermal dispersivity are negligible with respect to heat transfer by conduction and convection and should be set equal to zero. For Vandenbohede et al. 
(2009), thermal dispersivity is smaller than solute dispersivity. Therefore, the comparison between thermal and solute dispersion is not as easy as between thermal diffusivity and molecular diffusion.

The temperature breakthrough curve recorded at the recovery well can be converted into a recovered heat breakthrough to calculate that the recovered heat only represents $1 \%$ of injected heat. This indicates that a significant portion of injected heat is lost, most probably by heat exchange and storage in the porous medium. The lost can occur through the vadose zone, to the shaly bedrock or even laterally if the injection is not performed in a perfectly radial converging regime. This heat exchange must be especially significant in the vicinity of the injection well where the temperature contrast is very high (up to $25^{\circ} \mathrm{C}$ ). As the drawdown induced by the pumping is limited, it is also likely that a portion of heated groundwater simply does not reach the recovery well. Furthermore, due to the precision of the temperature probes, the heat breakthrough curve cannot be recorder at the pumping well after 5 days following injection. Nevertheless, a substantial amount of heat remains in the upper part of the aquifer 5 days after the injection. This can be seen e.g. at the upper screen of Pz11 (Figure 3) were the elevation of temperature is still more than $4{ }^{\circ} \mathrm{C}$ after 5 days. This remaining amount of thermal energy is too diluted when it reaches the recover well to induce a significant temperature difference captured by the temperature probe.

The normalized cumulative breakthrough curve for the napthionate indicates that $67 \%$ of the injected mass is recovered. The remaining $33 \%$ are most probably degraded since naphtionate degradation processes have already been observed on the experimental site. Brouyère (2001) obtained mean recovery ratios of $70 \%$ from pulse injections performed $25 \mathrm{~m}$ upgradient the recovery well, where the pumping rate was $52.6 \mathrm{~m}^{3} / \mathrm{h}$ inducing faster groundwater fluxes and therefore less time for degradation to occur.

\subsection{Temperature and solute breakthrough curve modeling using a semi-analytical transport model}


Temperature and naphtionate breakthrough curves were also interpreted using the TRAC software developed by BRGM (Gutierrez et al., 2012b), using the semi-analytical solution for tracer experiments in a radially converging flow field considering advection, dispersion, retardation and degradation, and a continuous injection of tracer or heat (Gutierrez et al., 2012a).

The naphtionate breakthrough curve is used to estimate the effective (transport) porosity $n_{e}$ and the longitudinal dispersivity $\alpha$ by fitting the model with focus on reproducing the first arrival and modal times. The $1^{\text {st }}$ order degradation coefficient $\lambda$ is also included in the fitting process as degradation of the naphtionate in the experimental site was highlighted by Brouyère (2001). Fitted and measured breakthrough curves are presented in Figure 6 . The fit focused on the first arrival, the rising and the modal time of the breakthrough curve. The tailings of the simulated curves do not perfectly match with the field data for three major reasons. The first one is that the well is screened across the entire thickness of the aquifer. This does not allow for a separate interpretation of heat transfer within the upper and the lower zone although it has been proved that groundwater flows heterogeneously in the aquifer. The second reason is that no immobile/mobile water transfer is used although it is likely to happen in this aquifer. And finally, the heat diffusion (conduction), whereas it is likely to play a more important role than in solute transport, is not taken into account explicitly within the analytical solution, it is rather gathered with the dispersivity in a dispersion factor. The values obtained for the parameters after the fitting process are given in Table 3 . The fitted effective porosity $(0.04)$ is in good agreement with Brouyère (2001) who obtain an effective porosity ranging from 0.037 to 0.055 based on 6 tracer tests performed around the pumping well at the same experimental site.

The temperature breakthrough curve was used in a second step for estimating the thermal retardation factor $R$ reflecting heat exchange between the groundwater and the aquifer solids. For heat transport, the $1^{\text {st }}$ order degradation coefficient $\lambda$ is set equal to 0 . The fitted and measured temperature 
breakthrough curves are presented in Figure 6 and the corresponding adjusted parameter values are summarized in Table 3.

The thermal retardation factor is given by (Hecht-Méndez et al., 2010):

$R=\frac{\rho_{m} c_{m}}{n \rho_{w} c_{w}}=\frac{C_{m}}{n C_{w}}$

where $C_{m}$ is the volumetric heat capacity of the saturated porous medium (total phase) $\left[\mathrm{J} / \mathrm{m}^{3} / \mathrm{K}\right], n$ is the total porosity [-], and $C_{w}$ is the volumetric heat capacity of the water $\left[\mathrm{J} / \mathrm{m}^{3} / \mathrm{K}\right]$.

With a total porosity of 0.11 for the experimental site (Brouyère, 2001), it is possible to estimate the volumetric heat capacity of the saturated porous medium $C_{m}$. The value obtained is equal to $2.30 \mathrm{MJ} / \mathrm{m}^{3} / \mathrm{K}$. This value, slightly lower than the value obtained with the energy balance, is consistent with the range of values found in the literature that ranges from 2 to $3.1 \mathrm{MJ} / \mathrm{m}^{3} / \mathrm{K}$ (Palmer et al., 1992, Wagner at al. 2013). Since the solute and heat breakthrough curve recorded at the recovery well is mainly due to fast groundwater flow in the lower part of the aquifer, the volumetric heat capacity determined on the breakthrough curve is mainly representative for the lower part of the aquifer.

\subsection{Energy balance of the heat tracer experiment}

The energy balance equation on a volume of porous medium corresponding to the portion of the aquifer investigated by the heat tracer experiment can be written as follows:

$\dot{M}_{i n j} c_{w} T_{i n j}+\left(\dot{M}_{\text {ext }}-\dot{M}_{i n j}\right) c_{w} T_{0}-\dot{M}_{e x t} c_{w} T_{e x t}-\dot{Q}_{\text {lost }}=M_{m} c_{m} \frac{d T_{e x t}}{d t}$

with $\dot{M}_{i n j}$ is the mass rate of water injected into the aquifer $[\mathrm{kg} / \mathrm{s}], c_{w}$ is specific heat capacity of water $[4181.3 \mathrm{~J} / \mathrm{kg} / \mathrm{K}], T_{\text {inj }}$ is the temperature of injected water $[\mathrm{K}], \dot{M}_{\text {ext }}$ is the mass rate of water abstracted 
from the aquifer $[\mathrm{kg} / \mathrm{s}], T_{0}$ is the initial temperature of groundwater $[\mathrm{K}], T_{\text {ext }}$ is the temperature of abstracted groundwater, representative of the saturated porous medium [K], $\dot{Q}_{\text {lost }}$ is the lost energy flux $[\mathrm{J} / \mathrm{s}], M_{m}$ is the mass of saturated porous medium $[\mathrm{kg}], c_{m}$ is the specific heat capacity of the saturated porous medium $[\mathrm{J} / \mathrm{kg} / \mathrm{K}]$.

The left side terms correspond respectively to the energy fluxes related to (1) the injection of hot water into the aquifer at mass flow rate $M_{i n j}\left(0.83 \mathrm{~kg} / \mathrm{s}\right.$ ) at temperature $T_{i n j}$ (in the injection well equal to $40{ }^{\circ} \mathrm{C}$, (2) groundwater in motion at the initial temperature of the aquifer $T_{0}\left(13.33^{\circ} \mathrm{C}\right),(3)$ groundwater withdrawal from the aquifer at temperature $T_{\text {ext }}$ (at the recovery well) and a mass flow rate $\dot{M}_{\text {ext }}$ $(8.33 \mathrm{~kg} / \mathrm{s})$, and (4) $\dot{Q}_{\text {lost }}$, the lost energy towards the unsaturated zones and the shaly bedrock. The right side term corresponds to storage of energy in the saturated porous medium. The unknowns of this the energy balance equation are the lost energy flux $\dot{Q}_{\text {lost }}$, the mass of the saturated porous medium $M_{m}$, and the specific heat capacity of the saturated porous medium $c_{m}$. The other variables correspond to data measured on the field (mass rates $\dot{M}$ and temperature $T$ ) or easily found in the literature (specific heat capacity of the water $c_{w}$ ).

The lost energy flux $\dot{Q}_{\text {lost }}$ can be estimated as follows. If the temperature of the saturated porous medium $T_{m}$ is constant for a certain period, the storage term (time derivative) vanishes and Equation (4) can be formulated as follows:

$\dot{Q}_{\text {lost }}=\dot{M}_{i n j} c_{w} T_{i n j}+\left(\dot{M}_{\text {ext }}-\dot{M}_{i n j}\right) c_{w} T_{0}-\dot{M}_{\text {ext }} c_{w} T_{\text {ext }}$

The heat injection, as performed during this $24 \mathrm{~h}$ test, did not last enough to create a steady state for the heat transfer within the aquifer. Therefore, the heat transfer parameters adjusted on the heat breakthrough curve (Table 3) have been used to simulate an extrapolated temperature breakthrough curve for a continuous heat injection scenario. The maximum temperature at the recovery well reaches 
$13.83^{\circ} \mathrm{C}$ after 17 days. This value is used as $T_{\text {ext }}$ in the equation (5) to calculate the lost energy flux $\dot{Q}_{\text {lost }}$ at $7.54 \cdot 10^{-2} \mathrm{MJ} / \mathrm{s}$.

Given that the lost energy flux $\dot{Q}_{\text {lost }}$ is known, it is now possible to calculate the volumetric heat capacity of the saturated porous medium $C_{m}$ by dividing the heat capacity of the saturated porous medium $M_{m} c_{m}$ by its volume $V_{m}$ :

$C_{m}=\frac{M_{m} c_{m}}{V_{m}}$

Steady state simulations using a numerical model allowed an estimation of the volume of aquifer interrogated by the heat tracer test. With a temperature cut-off value set at $0.01^{\circ} \mathrm{C}$, the heat spreads laterally up to $25 \mathrm{~m}$ (so way further Pz13 and Pz17) and stretches 3 meters upgradient the injection well. The volume $V_{m}$ is then $4025 \mathrm{~m}^{3}$ for this $7 \mathrm{~m}$ thick aquifer.

Using Equation (3) under transient conditions and considering the rising part of the heat breakthrough curve recorded at the recovery well (between 1 and 3 days after the start of the tracer injection) with a slope $\frac{d T_{m}}{d t}$ of $1.5 \cdot 10^{-6} \mathrm{~K} / \mathrm{s}, C_{m}$ is estimated at $2.54 \mathrm{MJ} / \mathrm{m}^{3} / \mathrm{K}$. The value estimated with the energy balance for this parameter is consistent with the range of values found in the literature that ranges from 2 to 3.1 $\mathrm{MJ} / \mathrm{m}^{3} / \mathrm{K}$ (Palmer ert al., 1992, Wagner at al. 2013).

\section{Conclusions}

The coupled heat and chemical tracer experiment we present in this paper provides an efficient way of estimating this parameter in the field using temperature and concentration measurements in the recovery well. At this first step of the modeling approach, temperature measured in the other piezometers was not explicitly used. However, these temperature measurements were very useful for improving our understanding of heat transfer in a highly heterogeneous and relatively stratified shallow alluvial aquifer. As the proportion of gravels progressively increases with depth, the hydraulic 
conductivity is higher in the lower part of the aquifer than in the upper part. Therefore, heat transfer is conduction/dispersion-dominated in the upper part of the aquifer and convection-dominated in the lower part. This creates a vertical temperature gradient leading to heat exchange from the upper part to the lower part of the aquifer. As this vertical temperature gradient progressively decreases with the distance from the injection piezometer, the related heat exchange also decreases.

The comparison between temperature and naphtionate breakthrough curves shows that heat transfer in the alluvial aquifer is slower and more dispersive than solute transport. This is mainly related to heat exchange between groundwater and aquifer solids. This process is proportional to the specific heat capacity of the porous medium which proves that in situ estimation of this parameter is particularly useful. The values of specific heat capacity estimated with the energy balance approach $\left(2.54 \mathrm{MJ} / \mathrm{m}^{3} / \mathrm{K}\right)$ and with the modeling of the temperature breakthrough curve at the recovery well $\left(2.30 \mathrm{MJ} / \mathrm{m}^{3} / \mathrm{K}\right)$ are close and consistent with the range of values found in the literature. Therefore, unlike the TRT, temperature and concentration measurements performed during such a coupled experiment allow estimating the specific heat capacity of the porous medium. Additionally, the data gathered potentially contain enough information for deducing the entire set of heat transfer parameters as well as their spatial distribution. However, this will require developing a complex numerical model of the experiment for estimating these parameters by calibration with inverse modeling. Chemical tracer data are optional for estimating heat transfer parameters. However, prior to the inverse modeling, they can be used for estimating common parameters in heat transfer and solute transport such as effective porosity or they can advantageously be included in the inverse modeling for better constraining the problem.

\section{Acknowledgments}

This work was supported by research grants provided by the University of Liège Research Council project no. $\mathrm{C}-11 / 33$. Thanks are due to two anonymous reviewers for providing useful review feedback. 


\section{References}

Anderson M.P., 2005. Heat as a ground water tracer. Ground Water, 43(6), 951-968.

Bear J., 1972. Dynamics of fluids in porous media. American Elsevier Publishing Company Inc., New York.

Bertermann D., Bialas C., Rohn J., 2013. ThermoMap - Area mapping of superficial geothermic resources by soil and groundwater data. Available at http://www.thermomap-project.eu/wpcontent/uploads/2012/04/Poster-ThermoMap-English-2012.pdf.

Brielmann H., Griebler C., Schmidt S.I., Michel R., Lueders T., 2009. Effects of thermal energy discharge on shallow groundwater ecosystems. FEMS Microbiology Ecology, 68, 273-286.

Brouyère S., 2001. Etude et modélisation du transport et du piégeage de solutes en milieu variablement saturé. PhD thesis, University of Liege, Belgium (in French).

Brouyère S., 2003. Modeling tracer injection and well - aquifer interactions: a new mathematical and numerical approach. Water Resources Research, 39(3).

Brouyère S., Batlle-Aguilar J., Goderniaux P., Dassargues A., 2008. A new tracer technique for monitoring groundwater fluxes: The Finite Volume Point Dilution Method. Journal of Contaminant Hydrology, 95, 121-140.

Dehner U., 2007. Bestimmung der thermischen Eigenschaften von Böden als Grundlage für die Erdwärmenutzung. Mainzer geowissenschaftliche Mitteilungen, 35, Mainz, 159-186 (in German). de Marsily G., 1986. Quantitative hydrogeology. Academic Press, San Diego. 
de Paly M., Hecht-Méndez J., Beck M., Blum P., Zell A., Bayer P., 2012. Optimization of energy extraction for closed shallow geothermal systems using linear programming. Geothermics, 43, 5765.

Domenico P.A., Schwartz F.W., 1998. Physical and chemical hydrogeology. John Wiley \& Sons Inc., New York.

Freedman V.L., Waichler S.R., Mackley R.D., Horner J.A., 2012. Assessing the thermal environmental impacts of an groundwater heat pump in southeastern Washington State. Geothermics, 42, 65-77.

Gehlin S., 2002. Thermal Response Test. Method development and evaluation. PhD thesis, Luleå University of Technology, Sweden.

Giambastiani B.M.S., Colombanii N., Mastrocicco M., 2013. Limitation of using heat as a groundwater tracer to define aquifer properties: experiment in a large tank model, Environmental Earth Sciences, 70, 719-728.

Gutierrez A., Klinka T., Thiéry D. 2012a. Manuel d'utilisation de TRAC : Aide à l'interprétation de raçages en milieux poreux. Final report BRGM/RP-60660-FR, 116P. Retrieved from http://trac.brgm.fr/spip.php?article24 (In French).

Gutierrez A., Klinka T., Thiéry D., 2012b. Validation du logiciel TRAC : Aide à l'interprétation de traçages en milieu poreux. Rapport BRGM/RP-59425-FR, 58 p., 43 fig., 1 ann. (in French).

Haehlein S., Bayer P., Blum P., 2010. International legal status of the use of shallow geothermal energy. Renewable and Sustainable Energy Reviews, 14(9), 2611-2625.

Hecht-Méndez J., Molina-Giraldo N., Blum P., Bayer P. 2010. Evaluating MT3DMS for heat transport simulation of closed geothermal systems. Ground Water, 48(5), 741-756

Hermans T., Vandenbohede A., Lebbe L., Nguyen F. 2012. A shallow geothermal experiment monitored with electric resistivity tomography. Geophysics, 77(1), B11-B21. 
Hermans T., Wildemeerch S., Jamin P., Orban P., Brouyère S., Dassargues A., Nguyen F. 2015.

Quantitative temperature monitoring of a heat tracing experiment using cross-borehole ERT.

Geothermics, 53, 14-26, doi: 10.1016/j.geothermics.2014.03.013.

Hopmans J.W., Simunek J., Bristow K.L., 2002. Indirect estimation of soil thermal properties and water flux using heat pulse probe measurements: geometry and dispersion effects. Water Resources Research, $38(1), 7-1-7-14$.

Ingebritsen S.E., Sanford W.E., 1998. Groundwater in Geologic Processes. Cambridge University Press, Cambridge, UK.

IRM Institut Royal Meteorologique de Belgique, 2013. Rapport annuel 2012. Available at http://www.meteo.be/meteo/view/fr/103541-Publications.html Jesußek A., Grandel S., Dahmke A., 2013. Impacts of subsurface heat storage on aquifer hydrogeochemistry. Environmental Earth Sciences, 69(6), 1999-2012.

Kersten M.S., 1949. Thermal properties of soils. Bulletin 28. Mineapolis: Engineering Experiment Station, University of Minnesota.

Lo Russo S., Civita M.V., 2009. Open-loop groundwater heat pumps development for large buildings: a case study. Geothermics, 38, 335-345.

Lo Russo S., Taddia G., Verda V., 2012. Development of the thermally affected zone (TAZ) around a groundwater heat pump (GWHP) system: a sensitivity analysis. Geothermics, 43, 66-74. Lund J.W., Freeston D.H., Boyd T.L., 2011. Direct utilization of geothermal energy 2010 worldwide review. Geothermics, 40(3), 159-180.

Molson J.W., Frind E.O., Palmer C.D., 1992. Thermal energy storage in an unconfined aquifer 2. Model development, validation and application. Water Resources Research, 28, 2857-2867. 
Palmer C.D., Blowes D.W., Frind E.O., Molson J.W., 1992. Thermal energy storage in an unconfined aquifer 1. Field injection experiment. Water Resources Research, 28, 2845-2866.

Sanner B., Hellström G., Spitler J., Gehlin S., 2005. Thermal response test-current status and worldwide application. Proc World Geothermal Congress 2005, Antalya, Turkey, 24th-29th April 2005.

Sanner B, Hellström G., Spitler J., Gehlin S. 2013. More than 15 years of mobile Thermal Response Test A summary of experiences and prospects. Proc European Geothermal Congress, Pisa, Italy, 3rd7th June 2013.Vandenbohede A., Louwyck A., Lebbe L., 2009. Conservative solute versus heat transport in porous media during push-pull tests. Transport in porous media, 76, 265-287. Vandenbohede,A., Hermans T., Nguyen F., Lebbe L., 2011. Shallow heat injection and storage experiment: heat transport simulation and sensitivity analysis. Journal of Hydrology, 409, 262-272. Wagner V., Li T., Bayer P, Leven C., Dietrich P., Blum P., 2013. Thermal tracer testing in a sedimentary aquifer: Field experiment (Lauswiesen, Germany) and numerical simulation. Hydrogeology Journal, 22, 1, 175-187.

Warner D.L., Algan U., 1984. Thermal impact of residential ground-water heat pumps. Ground water, 22, 6-12. 


\section{Figure captions}

Figure 1 The test site is located $13 \mathrm{~km}$ north east of Liège, Belgium, Western Europe, on the alluvial plain of the River Meuse.

Figure 2 The experimental setup consists in simultaneous injection of heat and chemical dye (naphtionate) tracer from Pz09 and monitoring of their breakthrough at the recovery pumping well (PP). Temperature is continuously monitored at piezometer Pz10 to Pz20. These piezometers are either single-screened in the whole alluvial aquifer made of sandy gravels, or double-screened with an upper screen in the finest part of the aquifer at its top, and a lower screen within the coarse gravels at the bottom of the aquifer.

Figure 3 Temperature breakthrough curves measured in each piezometer. The blue curves correspond to the lower part of the aquifer. The red curves correspond to the upper part of the aquifer. The green curves correspond to the mean temperature along the whole thickness of the aquifer.

Figure 4 Vertical temperature profiles monitored by DTS at the injection piezometer Pz09. After the injection stops, the heat is rapidly flushed out of the lower part of the piezometer although the temperature remains high at the top of the piezometer due to slower groundwater flow in the upper part of the aquifer.

Figure 5 Temperature and naphtionate breakthrough curves measured in the recovery well.

Figure 6 Fitted and measured breakthrough curves for the naphtionate and temperature. The fit has been focused on first arrival, modal time and rising part of the curve. Imperfect tailings fit is due to (1) a vertical integration on the whole aquifer thickness at the recovery well although the lower part responsible for shape of the curve in transport of solute and heat transfer, (2) no mobile/immobile 
water effect has been considered and (3) heat diffusion is not considered explicitly in the semi analytical solution used to interpret the curves. 


\section{Table captions}

Table 1 Thermal conductivity and volumetric heat capacity values estimated in the zone of the experimental site in the framework of the ThermoMap project (Bertermann et al., 2013).

Table 2 Darcy's fluxes $\left(10^{-4} \mathrm{~m} / \mathrm{s}\right)$ measured by the FVPDM are ten times higher in the lower part of the aquifer than in the upper part.

Table 3 Parameter values obtained after the fitting process for the naphtionate ant temperature breakthrough curves. 


\section{Revised Tables}

Click here to download Table: Wildemeersch-Coupled heat and chemical tracer-revised tables.docx

Table 1

\begin{tabular}{ccc}
$\begin{array}{c}\text { depth of layer } \\
{[\mathrm{m}]}\end{array}$ & $\begin{array}{c}\text { thermal conductivity } \\
{[\mathrm{W} / \mathrm{m} / \mathrm{K}]}\end{array}$ & $\begin{array}{c}\text { volumetric heat capacity } \\
{\left[\mathrm{MJ} / \mathrm{m}^{3} / \mathrm{K}\right]}\end{array}$ \\
\hline $0-3$ & $1.17 \pm 0.30$ & 2.24 \\
$3-6$ & $1.37 \pm 0.35$ & 2.22 \\
$6-10$ & $1.86 \pm 0.52$ & 2.34 \\
\hline
\end{tabular}

Table 2

\begin{tabular}{lcccccccccccc}
\hline Piezometer & 10 & 11 & 12 & 13 & 14 & 15 & 16 & 17 & 18 & 19 & 20 & Mean \\
\hline $\begin{array}{l}\text { Upper } \\
\text { screen }\end{array}$ & 3.50 & 6.56 & 3.37 & & 3.50 & 2.27 & 1.75 & & 1.22 & 0.87 & 1.97 & 2.78 \\
$\begin{array}{l}\text { Lower } \\
\text { screen }\end{array}$ & 59.93 & 19.03 & 22.31 & & 31.63 & 9.95 & 9.89 & 26.08 & 26.68 & 46.37 & 74.37 & 33.35 \\
\hline
\end{tabular}

Table 3

\begin{tabular}{lcc}
\cline { 2 - 3 } & naphtionate & temperature \\
\hline effective porosity $n_{e}[-]$ & 0.04 \\
longitudinal dispersivity $\alpha[\mathrm{m}]$ & 3 & \\
$1^{\text {st }}$ order degradation coefficient $\lambda\left[\mathrm{s}^{-1}\right]$ & $1.5 \cdot 10^{-5}$ & 0 \\
retardation factor $R[-]$ & 1 & 5 \\
\hline
\end{tabular}



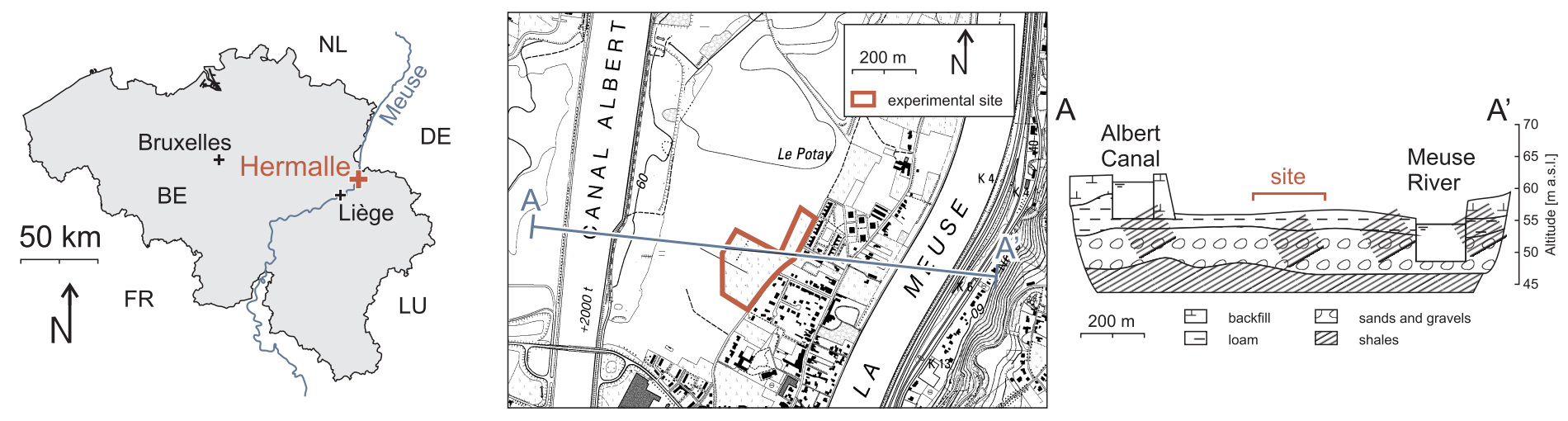


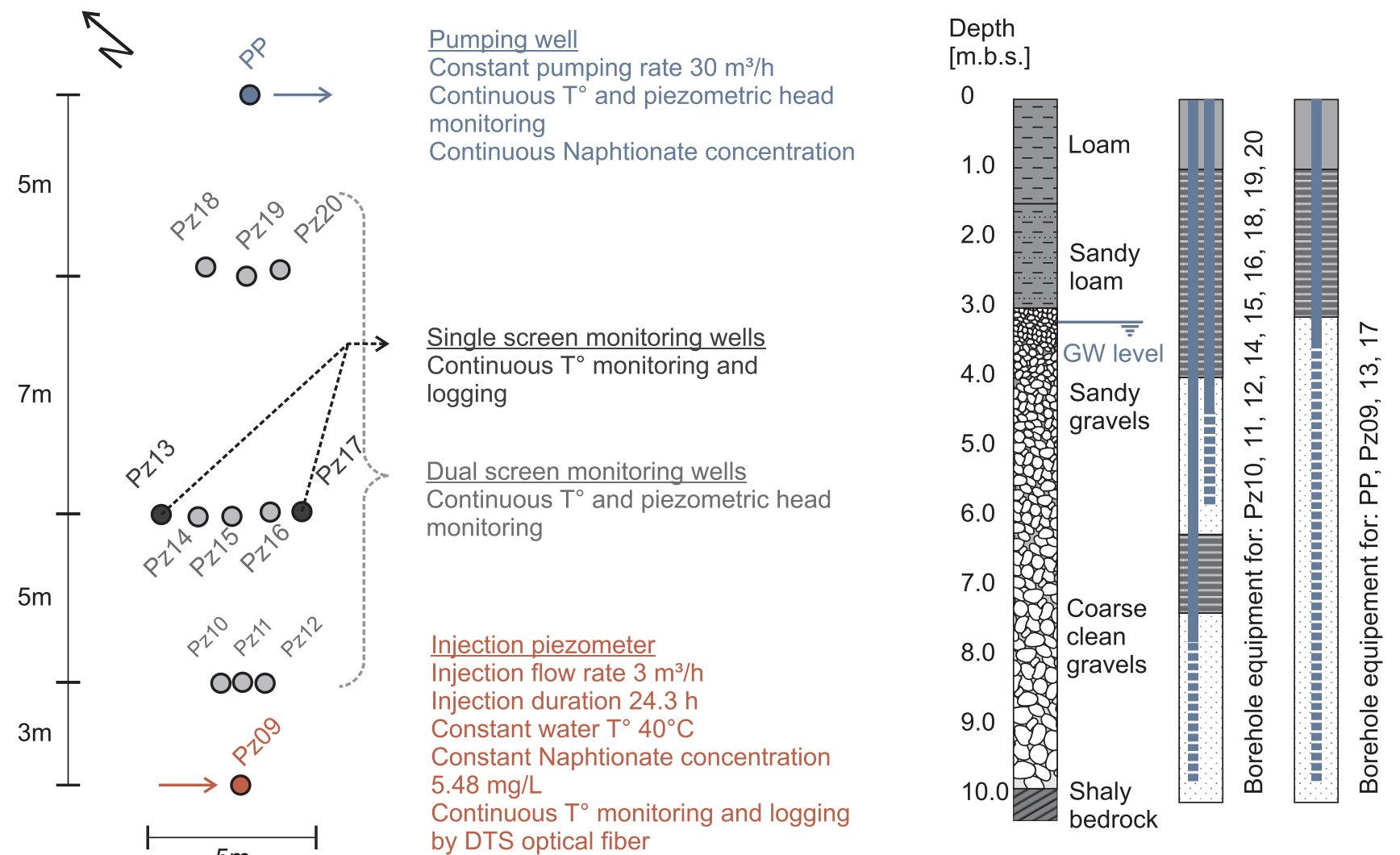

by DTS optical fiber 
Figure3
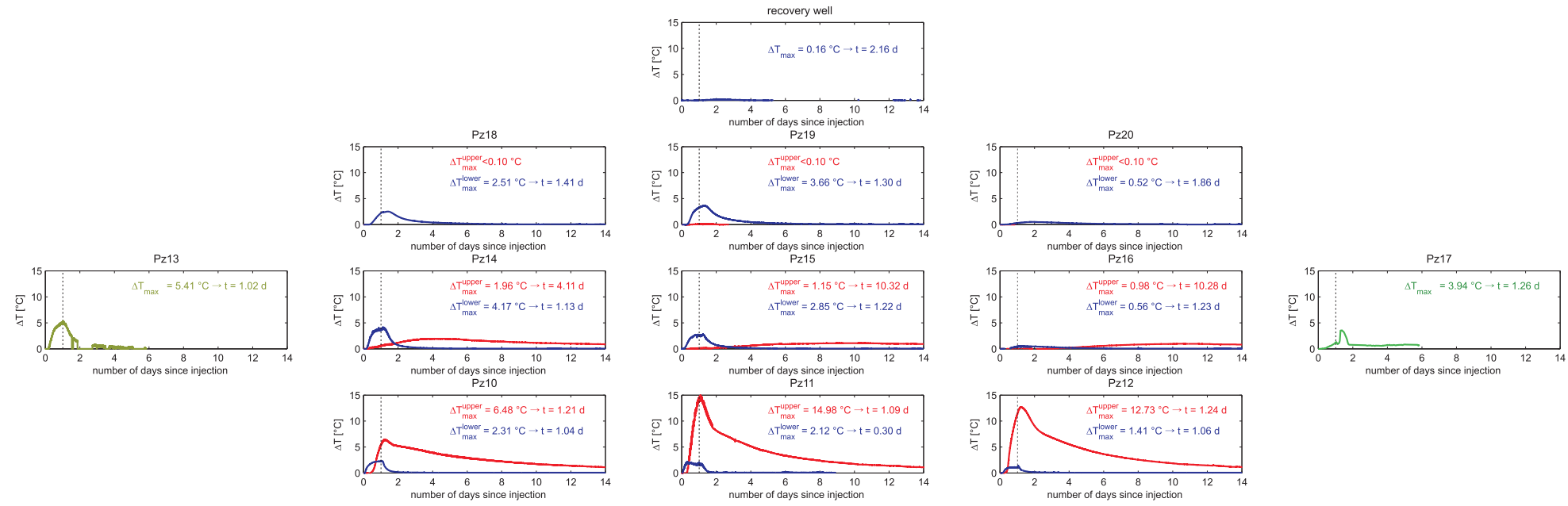


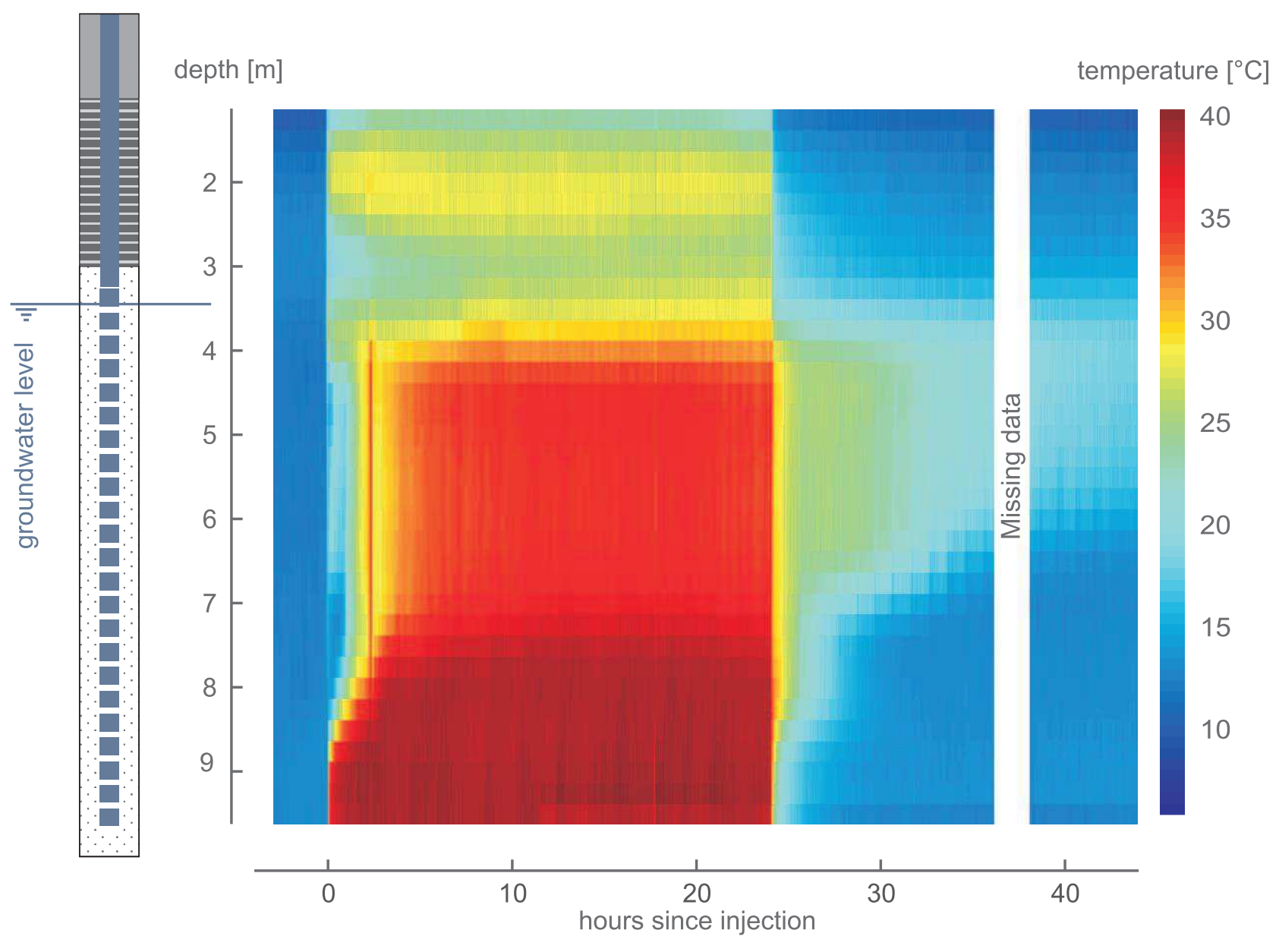




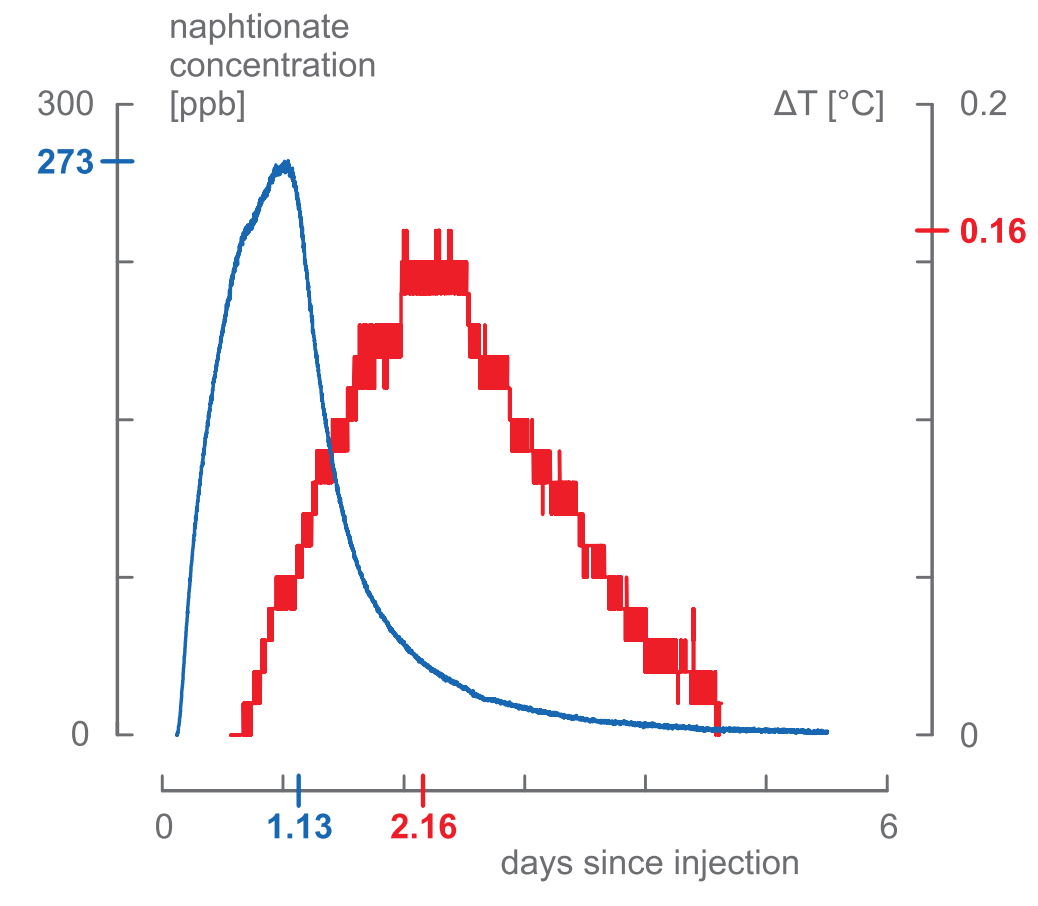

Figure5 

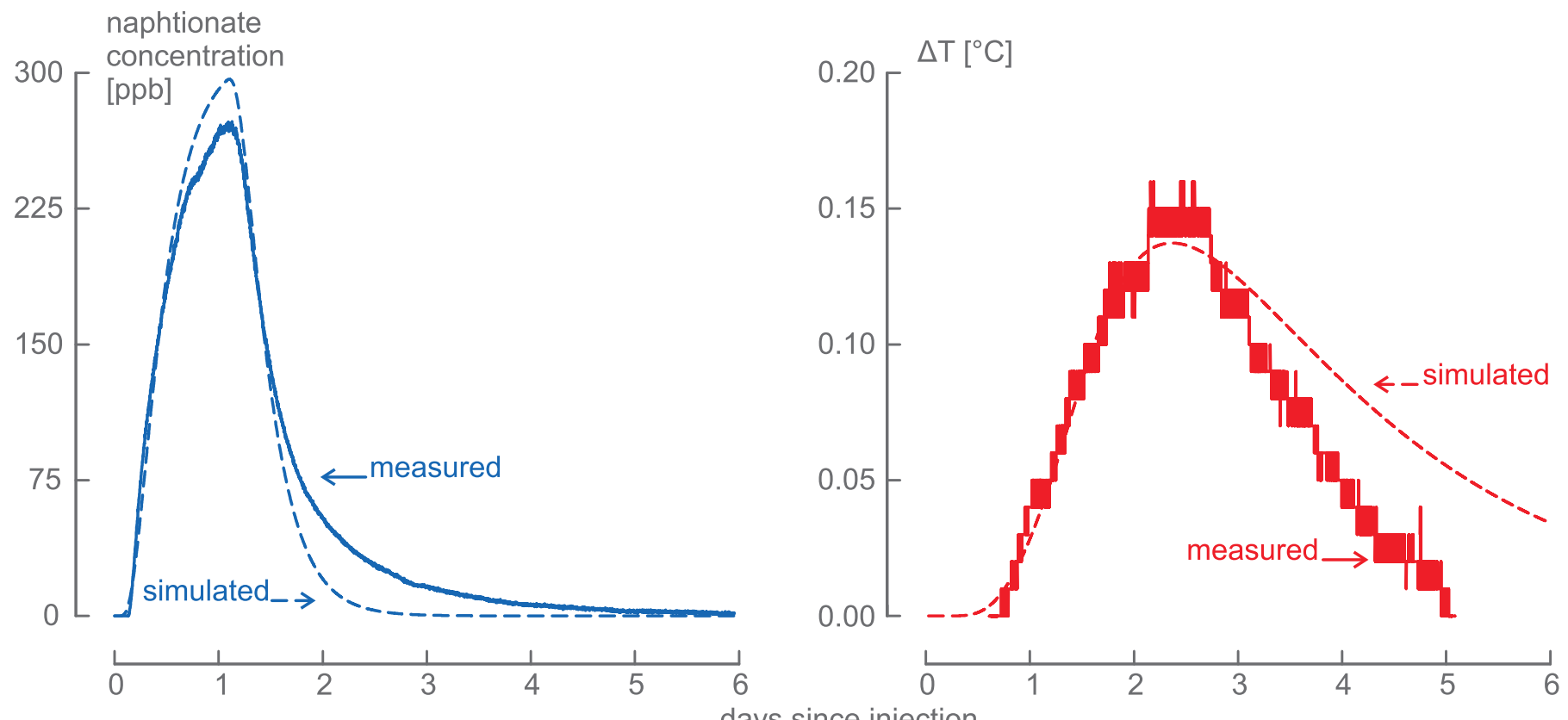

days since injection 